\title{
Risk Factors of Stroke in Young and Old age Group - A Comparative Study
}

MIAH M N A, ${ }^{1}$ AZHAR MA, ${ }^{2}$ RAHMAN $A,{ }^{3}$ HALDER D, ${ }^{4}$ AKTERUZZAMAN $M,{ }^{5}$ KUNDU N $C^{6}$

\begin{abstract}
:
Background: Stroke is an important cause of death and disability. Prevalence of stroke in Bangladesh differs with age. The risk factors in young differ in comparison to old age group. In this study risk factors of stroke in young in comparison to old age group were evaluated.
\end{abstract}

Objectives: To compare the risk factors associated with stroke in young adult and to those of old age group.

Methodology: This comparative study conducted in the department of Medicine and Neurology, Sir Salimullah Medical College \& Mitford Hospital, Dhaka from January 2008 to June 2009. One hundred two stroke patient of above 15 years of age were confirmed by CT scan or MRI of brain those were included in young and old age groups. The risk factors of stroke were defined in terms of hypertension, diabetes mellitus, dyslipidaemia, ischemic heart diseases, valvular heart disease, history of transient ischemic attack or stroke, smoking and oral contraceptive pill.

Results: Of total 102 cases 17 were young adults and 85 old patients between 19 to 100 years. Mean age young adult was 39.76 ( \pm 6.379 ) and old age was 65.06 ( \pm 11.238 ). $61.7 \%$ were male \& $38.2 \%$ were female and the ratio was $1.6: 1$. Amongst male $58.8 \%$ patients were smoker in each age group and only $2.9 \%$ old patients were alcoholic. Only $17.6 \%$ had previous history of transient ischemic attack or stroke in each age group. $58.8 \%$ of young and $48.2 \%$ of old were hypertensive. $7 \%$ old patients had history of ischemic heart disease. $5.9 \%$ of young and $2.4 \%$ of old patients had valvular heart disease but no patient had vasculitis. $16.7 \%$ old patients had diabetes mellitus. $4.9 \%$ of total patients (young $11.8 \%$ and $3.5 \%$ old) were oral contraceptive pill user. Out of all patients $24.7 \%$ old patients and $5.9 \%$ young adult was dyslipidaemic. Among all patients $66.7 \%$ patients had the Ischemic stroke and $33.3 \%$ patients had the hemorrhagic stroke. $68.2 \%$ old patients and $58.8 \%$ young patients had Ischemic stroke; $31.8 \%$ old patients and $41.2 \%$ young patients had hemorrhagic stroke.

Conclusion: In young age group smoking, transient ischemic attack or stroke, hypertension, valvular heart disease, oral contraceptive pill and in old age group smoking, transient ischemic attack or stroke, hypertension, Ischemic heart disease, diabetes mellitus and dyslipidaemia were found significant risk factors for development of stroke. So modification of risk factors may reduce the incidence of stroke.

Keyword: Stroke, risk factors, young, old age group.

1. Assistant Professor, Department of Medicine, Sir Salimullah Medical College, Dhaka.

2. Professor and Head, Department of Medicine, Sir Salimullah Medical College, Dhaka.

3. Registrar, Department of Neurology, Sir Salimullah Medical College Mitford Hospital, Dhaka.

4. Assistant Professor, Department of Medicine, Sir Salimullah Medical College, Dhaka

5. Assistant Registrar, Department. of Cardiology, Sir Salimullah Medical College Mitford Hospital, Dhaka

6. Associate Professor, Dept. of Neurology, Sir Salimullah Medical College, Dhaka.

Correspondence : Dr. Md. Nurul Amin Miah, Assistant Professor, Department of Medicine, Sir Salimullah Medical College, Dhaka.

\section{Introduction:}

It is predicted that stroke will soon become the first cause of death world wide but now it is one of the leading cause of death and disability in developed countries as well as developing countries like Bangladesh. Still now there is no remarkable curative treatment of stroke and stroke related physical disabilities. So we should take appropriate valuable measure against its prevention. The risk factors of stroke differ significantly between young adult and old age group. Risk factors of stroke in Bangladeshi population differ from that of other countries. At the same time risk factors in young differ in comparison to old age group.

In a recent study in Bangladesh the prevalence rates of stroke were 2.0,3.0, 2.0, 10.0, and 10.0 per 1000 within age groups of 
40-49 years, 50-59 years, 60-69 years, 70-79 years and 80 years to above age group respectively. Prevalence rates rose with age. People with age range $70-79$ years compared to 40 - 49 years age range is 4.988 (95\% CI 2.309 to 10.77$)$ times and people with age range $>80$ years compared to 40 to 49 years age range is 4.798 (95\% CI 1.597 to 14.416$)$ times more likely to have suffered from stroke. Prevalence rate was higher among men compared with women 3.44 and 2.41 per 1000 respectively (Odds ratio $=1.425,95 \%$ CI. $95 \%$ CI 0.779 to 2.608). ${ }^{1}$ There is no cure in management of stroke but prevention is possible by early detection and reducing the modifiable risk factors for stroke. This is very much important in the context of our country where medical facilities and resource is limited and most of the people live below average condition. With this study risk factors of stroke in young in comparison to old age group will be evaluated.

Stroke is a neurological disease, which is major cause of death and disability worldwide. Stroke kills about five million people each year making this the second major cause of death worldwide. At least fifteen million others have nonfatal stroke annually and about a third are disabled as a consequence. ${ }^{2}$ The word stroke is used to refer to a clinical syndrome, of presumed vascular origin, defined by rapidly developing signs of focal or global disturbance of cerebral functions lasting more than 24 hours or leading to death. ${ }^{3}$ It is the outward manifestation of a localized sudden interruption of the blood supply to some parts of the brain.

Stroke is predominating in the middle and late years of life. The incidence of stroke increases with age and affects many people in their golden years. It is uncommon below the age of 40 years and more common in male. Death rate following stroke is about $25 \% .{ }^{4}$ When stroke occurs in the age group from 15 to 45 years, is called stroke in young adults. ${ }^{5}$ Stroke in young adults is not uncommon but devastating and frequently no cause can be found. Cerebral infarction accounts for 80 to $85 \%$ of cases of stroke and 20 to $15 \%$ are caused by intracranial hemorrhages in the western world. ${ }^{6}$ Non modifiable risk factors of stroke include age. Sex, family history, race and ethnicity. Modifiable risk factors include hypertension, diabetes mellitus, cardiac diseases (particularly atrial fibrillation), hyperlipidaemia, smoking; transient ischemic attacks, asymptomatic carotid artery stenosis, alcohol abuse and physical inactivity. ${ }^{7}$ Stroke in young adults include a wide variety of disorders that are less frequently seen in older age groups. Though there are some overlapping in the risk factors between the two groups but there are some clearly distinct risk factors for stroke in young adults e.g. oral contraceptive pill, pregnancy, connective tissue disease with vasculities, hematological variables, drug abuse, smoking, congenital heart disease, family history of stroke, some genetic diseases etc.

Western reports shows that the higher incidence was not explained by a higher prevalence of premature atherosclerotic vasculopathy. Cardioembolization and non-atherosclerotic vasculopathies are relatively important cause of ischemic stoke as compared to atherosclerotic vasculopathy and small artery occlusion. ${ }^{8}$ It is important to find out the aetiologic factors and treatment of them adequately for preventing the recurrence. Stroke in young may influence the outcome \& may have a dramatic impact on the quality of life in survivors. ${ }^{9}$ It is the commonest neurological problems in relation to mortality and hospital admission and long-term disability in most industrialized population, which has a devastating impact on family and nation.

In Bangladesh there is no adequate data on incidence and mortality from stroke as well as young stroke. But the gravity of the situation can easily be assessed by the high incidence of hospital admission.

\section{Materials and Methods:}

This cross sectional comparative study was carried out in the department of Medicine and Neurology of Sir Salimullah Medical College \& Mitford Hospital in Dhaka city from January 2008 - June 2009. For this comparative study One hundred two of above 15 years of age stroke patients confirmed by CT scan or MRI of brain were included dividing young and old age group. Young Adult patient includes age range from 15 to 45 years and old age group includes age range above 45 years. The risk factors of stroke were defined in terms of hypertension, diabetes mellitus, dyslipidaemia, ischemic heart diseases, valvular heart disease, history of transient ischemic attack or stroke, smoking and oral contraceptive pill. Patients died or dropped out before investigations completed were excluded from the study. Detailed history was taken and thorough clinical examination was done in all cases. Some investigations like CBC with PBF, Blood Sugar, Serum Creatinine, Lipid profile, Serum Electrolytes, ECG, CT Scan of Brain were done in all cases. In Some selected cases MRI of brain, Echocardiography, Duplex study of neck vessels and ANA were done. For Statistical Analysis $\mathrm{P}$ value reached from Chi square test and Fisher exact tests to standard statistical analysis by using SPSS 12. Data were expressed as mean \pm SD.

\section{Results:}

In this study age distribution of patient shows in Table I that out of 102 patients 17 were young adult and 85 were old age 
group. Ages of young adults were $39.67 \pm 6.37$ years and old age group were $65.06 \pm 11.24$. In Table II Male in young were $41.17 \%$ and female were $58.82 \%$, in old age male were $65.88 \%$ and female were $34.11 \%$.

Table -III shows the difference of habitual variables in young and old age stroke patients. Many patients had more than one habits. Among 102 patients maximum 58.8\% patients were smoker in each age group and only $2.9 \%$ patients were alcoholic. Smoking had no significance difference in both age groups for development of stroke.

Table IV shows that $17.6 \%$ patients in each age group had the history of TIA or stroke. History of TIA or stroke showed statistically significant in development of stroke but no significant difference between two age groups. In young age group $58.8 \%$ and in old age group $48.2 \%$ patients had hypertension. Hypertension is statistically significant for development of stroke more in young age group. In old age group 7\% patients had IHD but none was in young age group. IHD is therefore significant for development of stroke in old age group. In young age group $5.9 \%$ and in old age group $2.4 \%$ patients had valvular heart disease is statistically significant for development of stroke in young age group. $20 \%$ of old age group was diabetic and young patients were nondiabetic. Diabetes had significant role in developing stroke in old age group. In young female $20 \%$ and in old female age group $10.34 \%$ had history of OCP use. OCP showed statistically significant role in developing stroke in young age group. In young adult 5.9\% and in old age group $24.7 \%$ were dyslipidaemic. Dyslipidaemia is statistically significant to develop stroke in old age group.

Table V shows among young age group 58.8\% had ischemic and $41.2 \%$ had hemorrhagic stroke. In old age group $68.2 \%$ had ischemic and $31.8 \%$ had hemorrhagic stroke. Between two groups ischemic stroke is more than that of hemorrhagic stroke in both age groups.

Table-I

Distribution of patients by age $(n=102)$

\begin{tabular}{lcc}
\hline & Young Adult & Old Age group \\
\hline Nnumber of Patients (n) & 17 & 85 \\
Mean age (yrs) & 39.76 & 65.06 \\
Std. Error of Mean & 1.547 & 1.219 \\
Std. Deviation & 6.379 & 11.238 \\
Minimum age (yrs) & 19 & 47 \\
Maximum age (yrs) & 45 & 100 \\
\hline
\end{tabular}

Table-II

Distribution of patients by Sex $(n=102)$

\begin{tabular}{lcccc}
\hline Sex & Young adult & Old Group & Total & Percent \\
\hline Male & 7 & 56 & 63 & 61.8 \\
Female & 10 & 29 & 39 & 38.2 \\
Total & 17 & 85 & 102 & 100.0 \\
\hline
\end{tabular}

Table-III

Distribution of habitual variables

\begin{tabular}{lccc}
\hline Parameters & $\begin{array}{c}\text { Young (\%) } \\
\text { adults } \mathrm{n}=17\end{array}$ & $\begin{array}{c}\text { Old age group } \\
(\%) \mathrm{n}=85\end{array}$ & $\begin{array}{c}\mathrm{P} \\
\text { value }\end{array}$ \\
\hline Smoking & $10(58.8)$ & $50(58.8)$ & $<0.05$ \\
Alcohol & 0 & $3(2.9)$ & $<0.05$ \\
\hline
\end{tabular}

Table-IV

Distribution of risk factors

\begin{tabular}{lccc}
\hline Parameters & $\begin{array}{c}\text { Young } \\
\text { adults (\%) }\end{array}$ & $\begin{array}{c}\text { Old age } \\
\text { group (\%) }\end{array}$ & $\begin{array}{c}\mathrm{P} \\
\text { value }\end{array}$ \\
\hline $\begin{array}{l}\text { History of TIA or } \\
\text { stroke }\end{array}$ & $3(17.6)$ & $15(17.6)$ & $<0.001$ \\
Hypertension & $10(58.8)$ & $41(48.2)$ & $<0.05$ \\
IHD & 0 & $6(7)$ & $<0.05$ \\
Valvular Heart Disease & $1(5.9)$ & $2(2.4)$ & $<0.001$ \\
DM & 0 & $17(20)$ & $<0.001$ \\
OCP & $2(20)$ & $3(10.34)$ & $<0.001$ \\
Dyslipidaemia & $1(5.9)$ & $21(24.7)$ & $<0.001$ \\
\hline
\end{tabular}

Table-V

Type of strokes

\begin{tabular}{lcc}
\hline Parameters & $\begin{array}{c}\text { Young } \\
\text { adults (\%) }\end{array}$ & $\begin{array}{c}\text { Old age } \\
\text { group (\%) }\end{array}$ \\
\hline Type of stroke & & \\
Ischemic & $10(58.8)$ & $58(68.2)$ \\
Hemorrhagic & $7(41.2)$ & $27(31.8)$ \\
\hline
\end{tabular}

\section{Discussion:}

This study done on stroke patients is time demanding since it is considered as coming epidemic as labeled by WHO. In this study 17 'young adults' were included and 85 were included in 'old age group'. Of 17 young adults mean age was $39.76 \pm 6.379$ years with minimum 19 to maximum 45 years. Of 85 old patients mean age was $65.06 \pm 11.238$ years 
ranging from 47 to 100 years. The number of patients in old age group is five times more than that of young age group. The incidence increased with age. ${ }^{10}$ This study also correlates with a study on the risk of subarachnoid and intracerebral hemorrhages in blacks as compared with whites that age is the most important risk factor for spontaneous $\mathrm{ICH}$; incidence increases exponentially with advancing age. ${ }^{11}$

In this study, female patients were more (10) in number than male (7) in young age group, on the other hand male patients were almost double (56) than female (29) in old age group. Male and female ratio of stroke patients was 1.61 indicating that stroke is a male predominant disease. In a similar study done previously which was a hospital based study on risk factors for cerebral infarction in terms of hypertension, diabetes mellitus, ischaemic heart disease, smoking, dyslipidaemia, transient ischaemic attacks (TIAs), carotid artery stenosis and family history of stroke. Male were slightly predominant than female $(51 \%$ vs $49 \%){ }^{2}$ The present hospital based study may not reflect the actual ratio in the community because of social deprivation, superstition and low socioeconomic status and male patients seek more medical attention than female.

Many patients had more than one habit. Among 102 patients maximum $58.8 \%$ patients were smoker in both age group and only $2.9 \%$ patients were alcoholic. Smoking was found to be a significant risk factor in majority of patient between the two age groups but alcohol was found to be responsible in older age group. This study is similar to that a meta-analysis of relation between cigarette smoking and stroke mentioned that cigarette smoking increases risk (RR) of ischemic stroke nearly two times, with a clear dose-response relation. ${ }^{12} 17.6 \%$ patients in both age groups had the history of TIA or stroke. Previous history of TIA or stroke is significant for development of stroke in both age groups. Our study is similar to that a prospective study on reevaluation of transient ischemic attacks as a risk factor for death and described the average risk of stroke in patients with TIA is about 4\%. After adjustment for major cardiovascular risk factors predisposing a patient to stroke. TIA remains a significant independent risk factor for both stroke and myocardial infarction. ${ }^{13} 50 \%$ of total patients had hypertension. In young age group $58.8 \%$ and in old age group $48.2 \%$ patients had hypertension. Hypertension is statistically significant for development of stroke in young.

Out of 102 patients 5.9\% had IHD and all are in old age group. In old age group 7\% patients had IHD. IHD is significant for development of stroke in old age group. Myocardial disease has long been recognized as a risk factor for stroke. ${ }^{10}$ In the Framingham Study, using multivariate analysis found that risk of stroke was increased two fold by coronary heart disease, threefold by electrocardiographic left ventricular hypertrophy, and threefold to fourfold by cardiac failure. ${ }^{10}$

In young age group $5.9 \%$ and in old age group $2.4 \%$ patients had mitral valvular heart disease. Mitral valvular heart disease is statistically significant for development of stroke in young age group. Prospective studies with more stringent diagnostic criteria for mitral valve prolapse suggest that the risk of stroke is low in subjects with prolapse uncomplicated by endocarditis or AF. Another valvular risk factor for stroke is mitral annular calcification. In the Framingham Study mitral annular calcification was associated with a doubled rate of stroke. As with mitral stenosis, the presence of AF and mitral annular calcification resulted in an amplification of risk for stroke. With both AF and annular calcification, stroke risk was increased fivefold, compared with a doubling in stroke risk with either factor present alone ${ }^{14}$

$20 \%$ of old age group was diabetic and young patients were free from diabetes mellitus. Diabetes has significant role in developing stroke in old age group. Our study is similar to that in Glucose intolerance and 22-year stroke incidence that persons with diabetes have an increased susceptibility to atherosclerosis and an increased prevalence of atherogenic risk factors, notably hypertension, obesity, and abnormal blood lipids. The studies of stroke patients and prospective epidemiological studies have confirmed an independent effect of diabetes with a relative risk of ischemic stroke in persons with diabetes from 1.8 to 3.0. Among Hawaiian Japanese men in the Honolulu Heart Program, those with diabetes had twice the risk of thromboembolic stroke of persons without diabetes that was independent of other risk factors. In a population-based cohort in Rancho Bernardo, persons with diabetes had a risk factors adjusted relative risk of stroke of 1.8 in men and 2.2 in women. In Framingham study, persons with glucose intolerance have double the risk of brain infarction in comparison to nondiabetic person. ${ }^{15}$

Out of female stroke patients 20\% young female and $10.3 \%$ old female were OCP user. OCP has statistically significant role in developing stroke in young age group studied on oral contraceptive pill (OCP) and mentioned that oral contraceptives with an estrogen content $>50 \mu \mathrm{g}$, the preparations used in the 1960s and 1970s, were strongly associated with risk for stroke. Recently a study of low-dose oral contraceptives ( $<50 \mu \mathrm{g}$ estrogen) disclosed no increased risk of stroke in more than 3.6 million woman-years of observation 16

In young adult $5.9 \%$ and in old age group $24.7 \%$ were dyslipidaemic. Dyslipidaemia is statistically significant to 
develop stroke in old age group. This is similar to the study stated that the association between dyslipidaemia and the risk of ischaemic stroke, specially cortical type. In the case control study among other risk factors total serum cholesterol and LDL-cholesterol levels were raised in both cortical and lacunar infarct. HDL-cholesterol levels were significantly low in cases $(70 \%)$ compared to control subjects $(26.7 \%)$. Serum triglyceride levels were raised in $60 \%$ of case group and $26.7 \%$ of control subjects. ${ }^{17}$

Among 102 patients majority $66.7 \%$ had the Ischemic stroke in both age groups. In young age group $58.8 \%$ had ischemic and $41.2 \%$ had hemorrhagic stroke. In old age group $68.2 \%$ had ischemic and $31.8 \%$ had hemorrhagic stroke. Between two groups ischemic stroke is more than that of hemorrhagic stroke in both age groups. This study was consistent to similar that ischaemic stroke is more than that of haemorrhagic stroke. ${ }^{18}$ This study therefore reveals that smoking, TIA, Hypertension, VHD, OCP, IHD diabetes mellitus and dyslipidaemia are the risk factors for development of stroke.

\section{Conclusion:}

In this study, in younger age group smoking, TIA, Hypertension, VHD and OCP and in older age group smoking, TIA, Hypertension, IHD diabetes mellitus and dyslipidaemia are the risk factors for stroke. Among the risk factors those are modifiable need special attention for the prevention of stroke.

In this study the risk factors for stroke both in young and old age groups were found hypertension, cardiac diseases, diabetes mellitus, dyslipidaemia, smoking, oral contraceptive pill. All of these risk factors are modifiable and need attention for the prevention of stroke.

By controlling hypertension, diabetes mellitus, avoidance of smoking,and controlling of dyslipidaemia we can reduce the incidence of stroke to a great extent. Community awareness and actions if could be combined with awareness of health care provider could have a significant impact on the primary and secondary prevention of strokes in our community.

\section{Conflict of Interest : None}

\section{References:}

1. Mohammad QD, 'Prevalence of stroke in a Bangladeshi population aged forty years and above: a population based study', (Unpublished)

2. Safeer M, Tariq M, Rahman Ubaid ur. Frequency of risk factors of cerebral infarction in stroke patients. A study of 100 cases in Naseer Teaching Hospital, Peshawar, Pakistan.. Pak J Med Sci, 2008; 24. 1: 109-13
3. World Health Organization Cerebrovascular disorders: a clinical and research classification.43. Geneva, World Health Organization; 1978

4. Remanes GJ. Head neck and brain. Cunnigham's Manual of Practical Anatomy $15^{\text {th }}$ ed. Oxford, Oxford University Press; 1986: 207-300

5. Frank M. Vatsu, choplu 41. Levis P. Rowland mesitts Neurolgy. $10^{\text {th }}$ ed. philadel phia. USA. 2000

6. Warlow CP, Dennis MS, Van Gijn J, Hankely Gt, Sandercock PAG, Bamford J, et al. Stroke: A practical guideline to management, $2^{\text {nd }}$ ed. Blackwell scientific publications, Oxford; 2000

7. Sacco RL, Benjamin EJ, Broderick JP, Dyken Mark, Easton JD, Feinberg WM.1997, 'Risk factors'. Stroke, vol.28: 150717. wm. Risk factors of stork. 1997; 28: 150-17

8. Kristensen B, Malp J, Carlberg B et al. Epidemiology and etiology of ischemic stroke in young adults aged 18-44 yrs in Northern Sweden. Stroke, 1997; 28(9): 1702-9

9. Manini C; Totaro R; De-Santis F; Cinacarelli, Baldassarre M; Carolei A. Stroke. 2001 Jan: 32 (1): 52

10. Wolf PA, Abbott RD, Kannel WB. Atrial fibrillation as an independent risk factor for stroke: the Framingham Study. Stroke. 1991, Aug; 22(8):983-8

11. Broderick JP, Brott T, Tomsick T, Huster G, Miller R. The risk of subarachnoid and intracerebral hemorrhages in blacks as compared with whites. N EnglandJ Med. 1992; 326(11):733-6

12. Shinton R, Beevers G; Meta-analysis of relation between cigarette smoking and stroke. BMJ,1989;298:789-94

13. Howard G, Evans GW, JR Crouse 3rd, JF Toole, JE Ryu, C Tegeler, J Frye-Pierson, E Mitchell and L Sanders. A prospective reevaluation of transient ischemic attacks as a risk factor for death and fatal or nonfatal cardiovascular events; Stroke, 1994; 25:342-5

14. Benjamin EJ, Levy D, Vaziri SM, D’Agostino RB, Belanger $\mathrm{AJ}$, Independent risk factors for atrial fibrillation in a population-based cohort. The Framingham Heart Study. JAMA. 1994, 16; 271(11):840-4

15. Burchfield CM, Curb JD, Rodriguez BL, Abbott RD, Chiu D, Yano K. Glucose intolerance and 22-year stroke incidence. Stroke. 1994; 25(5):951-7

16. Petitti DB, Sidney S, Bernstein A, et al. Stroke in Users of Low-Dose Oral Contraceptives. NEJM, 1996;335:8-15

17. Sarker T K, Kuddus M R, Khan M R K, Anwar Ullah AKM, Islam M R, Haque A; Dyslipidaemia in Cortical Versus Subcortical Infarction. Bangladesh Journal of Neuroscience. 2008, 24; 1:24-33

18. Lindsay KW, Bone I, Callander R. Neurology and Neurosurgery illustrated. $4^{\text {th }}$ ed. Edinburgh: Churchill Livingstone; 2004:238-97 